\title{
Learning, experience and cognitive factors in the presence experiences of gamers: An exploratory relational study
}

\author{
David Nunez \\ Department of Psychology \\ University of Cape Town \\ dnunez@humanities.uct.ac.za
}

\author{
Edwin Blake \\ Collaborative Visual Computing Lab \\ University of Cape Town \\ edwin@cs.uct.ac.za
}

\begin{abstract}
This paper presents a large scale $(N=101)$ exploratory relational study of computer gamers' experiences and habits related to presence. The study posited and examined the effect of two presence maximization strategies (controlling distracters and maintaining updated computer hardware) and two hypothetical cognitive styles (thematic inertia and capacity to integrate non-diagetic information) on gamers' rating of the importance of presence in games. The data show that frequency of game playing, but not game playing experience, affect self-rated presence importance, and that presence importance does not decline with experience. The data also suggest that presence maximization strategies are erratically effective in improving gaming experiences, and that the capacity to integrate non-diagetic information (but not thematic inertia) is a reliable predictor of self-rated presence importance.
\end{abstract}

\section{Introduction}

The role of cognition in presence has attracted some research attention in the past few years. The focus of this of research has been on isolating particular causal variables through experimental methods (for instance [1] or [2]). While this strategy has been fruitful, it is of limited use in producing new models for further investigation. This type of exploratory investigation is best done by examining natural relationships between large numbers of factors in large samples. This paper presents an exploratory relational study which was designed to examine the role of learning, experience and cognitive strategies to maximize presence in habitual users of virtual environments (VEs). For this study, we used computer gamers as the population, as we felt that this represented a large group of habitual VE users with a wide degree of variance in both VE usage experience and quality of presence experiences.

\subsection{Time, experience and self-rated importance of presence}

A number of experimental studies have found relationships between presence and various time and experience related factors such as age (e.g. [3]), game playing experience (e.g. [4]) and previous exposure to virtual environments (e.g. [5]). While such experimental studies have provided valuable insights, we feel that their ecological validity is limited (as is indeed the case for experiments in general [6]) by their use of a limited number of VE conditions from which they draw presence scores. This study thus aims to examine an average degree of presence during game playing in a general sense, in an effort to increase the generalizability of our findings. Rather than asking participants to report on any one recent presence experience, we asked them to rate how important they consider presence to be to their gaming (we call this self-rated presence importance). We reasoned that if gamers have enjoyable or compelling presence experiences while gaming, their ratings of presence importance will be higher. We measured presence importance by means of self-report items such as "A game should make me feel as if I am transported to inside the game world." and "I prefer games which create a sense of being in a place”.

\subsection{Presence maximization strategies}

We conjectured that if it is possible to manipulate one's gaming environment and habits to maximize presence, then it is highly probable that gamers would have discovered and evolved these techniques on their own. Furthermore, if gamers have developed presence maximization strategies, then the use of such strategies probably varies with time-related factors (length of time playing, age, etc). We identified two possible presence maximization strategies from the literature which the average gamer could easily implement on a regular basis: minimizing attention distracters [7, 8], and improving display fidelity by maintaining up-to-date computer equipment $[9,10]$.

\subsection{Cognitive styles and presence}

We were interested in finding evidence of particular cognitive styles which affect presence. We hypothesized two possible factors: thematic inertia and the capacity to integrate non-diagetic information.

Thematic inertia is the term we use to describe the tendency of subjects to engage in thematically similar activities - for instance, after watching a film with a certain theme, a high thematic inertia subject might read a book with the same theme. As thematic inertia can be linked to schemata activation [11], we theorize that individuals in whom schemata activation degrades slowly will tend to show a higher degree of thematic inertia. Furthermore, if 
presence is associated with schemata activation (as argued in [1]), then it is reasonable to suggest that thematic inertia might be a correlate of presence.

The second cognitive factor is the capacity to integrate non-diagetic information. In film, the term 'nondiagetic' refers to information which does not emanate from the story world (e.g. background music or narration). According to constructionist models of presence (e.g. [7] or [12]), presence is a function of how information from various sources is integrated into a coherent whole. Although non-diagetic information reduces the fidelity or realism of a system, it is reasonable that, if it is cognitively integrated correctly, it could contribute to presence.

\section{Exploratory study}

The study was advertised as a 'computer gaming habits survey' to various computer science classes, and the survey itself was posted on-line. A total of 101 responses were collected over a one-week period. Only 3 respondents were women $(2.97 \%)$. The mean age was 22.13 years (s=3.23), with a minimum of 17 and a maximum of 34 .

\subsection{Method}

We created a 40 item instrument measuring 10 factors. 6 of these were time and learning related factors (see Table 1), and the other 4 were cognitive and experiential factors (see Table 2). For most items, a Likerttype response format was used.

\begin{tabular}{|l|c|l|}
\hline \multicolumn{1}{|c|}{ Factor } & $\begin{array}{c}\text { No. } \\
\text { items }\end{array}$ & \multicolumn{1}{|c|}{ Example Item } \\
\hline $\begin{array}{l}\text { Length of time } \\
\text { playing presence } \\
\text { games }\end{array}$ & 3 & $\begin{array}{l}\text { How long have you } \\
\text { been playing first } \\
\text { person shooters? }\end{array}$ \\
\hline $\begin{array}{l}\text { Frequency of } \\
\text { playing presence } \\
\text { games }\end{array}$ & 3 & $\begin{array}{l}\text { How often do you play } \\
\text { simulators? }\end{array}$ \\
\hline $\begin{array}{l}\text { Frequency of } \\
\text { playing } \\
\text { presence games }\end{array}$ & 3 & $\begin{array}{l}\text { How often do you play } \\
\text { fighting games? }\end{array}$ \\
\hline $\begin{array}{l}\text { Knowledge of } \\
\text { computers }\end{array}$ & 1 & $\begin{array}{l}\text { How much knowledge } \\
\text { do you have about how } \\
\text { computers work? }\end{array}$ \\
\hline $\begin{array}{l}\text { Knowledge of } \\
\text { games }\end{array}$ & 1 & $\begin{array}{l}\text { How you have about how } \\
\text { computer games works? }\end{array}$ \\
\hline Age & Your age: \\
\hline
\end{tabular}

Table 1: Time-related and learning factors.

\subsection{Categorization of game types}

For this study, we broadly divided computer games into two categories: those which aim to produce presence ('presence games') and those which do not ('nonpresence games'). Presence games include among others simulators, role-playing games and first-person shooters, while non-presence games include real-time strategy, abstract puzzles and fighting games.

\section{Results}

\subsection{Learning and experience effects}

We conjectured that how important a player considers presence might be a function of learning or experience. We tested a linear regression model to predict the self-rated importance of presence in games using all six time-related factors as predictors $(\mathrm{F}=2.78$; $\mathrm{df}=6,66$; $p<0.017 ; \mathrm{R}^{2}=0.202$ ). By examining the partial regressions to control for inter-variable dependencies, we found the only significant predictor to be frequency of presence game playing (partial $\mathrm{r}=0.351 ; \mathrm{t}(66)=3.04 ; p<0.0033$ ). When we examined each of the six items composing the self-rated importance of presence factor, we found that one item ("The quality of a game's sounds are very important for my game experience.”) was also inversely predicted by frequency of non-presence game playing (partial $r=-0.25$; $\mathrm{t}(66)=-2.11 ; p<0.037)$.

\begin{tabular}{|l|c|l|}
\hline \multicolumn{1}{|c|}{ Factor } & $\begin{array}{c}\text { No. } \\
\text { Items }\end{array}$ & \multicolumn{1}{c|}{ Example Item } \\
\hline $\begin{array}{l}\text { Integration of non- } \\
\text { diagetic } \\
\text { information }\end{array}$ & 5 & $\begin{array}{l}\text { Inappropriate music in a } \\
\text { game can ruin the game } \\
\text { experience for me. }\end{array}$ \\
\hline $\begin{array}{l}\text { Self-rated } \\
\text { importance of } \\
\text { presence }\end{array}$ & 6 & $\begin{array}{l}\text { A game should make } \\
\text { me feel as if I am } \\
\text { transported to inside the } \\
\text { game world. }\end{array}$ \\
\hline $\begin{array}{l}\text { Thematic inertia } \\
\text { After watching a TV } \\
\text { program or film, I often } \\
\text { feel like playing a game } \\
\text { that is similar to the } \\
\text { film or program. }\end{array}$ \\
\hline $\begin{array}{l}\text { Presence } \\
\text { maximization }\end{array}$ & 6 & $\begin{array}{l}\text { When I play, I turn off } \\
\text { the lights and try to } \\
\text { keep the room dark. }\end{array}$ \\
\hline
\end{tabular}

Table 2: Cognitive and experiential factors

Only one item ("For me, the most important aspect of game playing is the ability to explore other worlds.”), was not predicted by time-related factors at all. The lack of time or learning effect on this item is probably attributable to the wording of the item. Although some players may enjoy exploring game worlds (a high-presence activity), most games make exploration a secondary activity - the player's primary goals (winning a fight, solving a puzzle, etc.) are often non-presence activities.

\subsection{Learning to maximize presence}

We examined the role of time and learning related factors in players' presence maximization strategies. Again, a multiple regression analysis was computed with all six time related factors as predictors for presence maximization strategies $\left(\mathrm{F}=2.83 ; \mathrm{df}=6,66 ; p<0.016 ; \mathrm{R}^{2}=0.204\right)$. Only knowledge of the workings of computer games was a 
significant predictor (partial $\mathrm{r}=-0.311 ; \mathrm{t}(66)=-2.66$; $p<0.0097$ ). Interestingly, the partial correlation shows that higher knowledge of game workings is associated with reduced efforts to manage presence.

This finding suggests that gamers who understand games more (and presumably the reliance of modern games on specialized computer hardware) would at least make an effort to keep their equipment up to date. We hypothesized that maintaining updated computer equipment may be beyond the economic reach of our sample of university students, and this would thus confound the finding. We found evidence of this when comparing the two items "As far as I can afford it, I make sure my computer has the best hardware for playing games." and "I will consider upgrading my computer to play a particular game.” How long the players had been playing presence games was indeed a significant predictor for this second item (partial $\mathrm{r}=0.28 ; \mathrm{t}(66)=2.39 ; p<0.019)$, but not for the first.

For the distraction related items, there were good indications that time-related factors play a role. For the item "If I am disturbed while I am playing, it ruins the experience for me.”, both age (partial $\mathrm{r}=0.25$; $\mathrm{t}(66)=2.057$; $p<0.043$ ) and how long the player had been playing presence games (partial $\mathrm{r}=0.29$; $\mathrm{t}(66)=2.52 ; p<0.014$ ) were significant predictors.

\subsection{Effectiveness of presence maximization strategies}

We were interested in the extent to which players' strategies for maximizing their presence were effective. Again, we used a multiple regression analysis with the presence maximization factors as a predictor for self-rated presence importance. The subsequent model was significant, although it explained only a small amount of the dependent variable's variance $(\mathrm{F}=18.87$; $\mathrm{df}=1,99$; $p<0.0005 ; \mathrm{R}^{2}=0.15$ ).

An item-by-item investigation of the self-rated presence importance factor showed that only two of the six items in the factor failed to show this pattern. The items "The quality of a game's sounds are very important for my game experience.” and "I prefer games which create a sense of being in a place" were not predicted by presence maximization strategies.

\subsection{Cognitive factors and time/learning effects}

We first examined relationships between our two cognitive factors (thematic inertia and the capacity to integrate non-diagetic information) and the six time-related factors. As the rate of schemata activation and decay is probably set at an early age and changes little over time [11] we expected no time effects on thematic inertia. Using a multiple regression analysis with the six time factors as predictors, we indeed found no significant effect on thematic inertia $(\mathrm{F}=0.89 ; \mathrm{df}=6,66 ; p<0.505)$.

For the integration of non-diagetic information factor, the picture is theoretically more complex. Some theorists propose that this integration task is not innate, but learned as one becomes more literate in decoding the medium [8, 13]. If this is true, then we expect to see learning effects. We did indeed find a significant effect. A multiple regression on capacity to integrate non-diagetic information with time factors as predictors was significant $\left(\mathrm{F}=2.42 ; \mathrm{df}=6,66 ; p<0.036 ; \mathrm{R}^{2}=0.18\right)$. Of the six time factors, only length of time playing presence games is significant (partial $\mathrm{r}=0.365 ; \quad \mathrm{t}(66)=3.191 ; \quad p<0.002$ ). Although this result can be interpreted as supporting a 'learning to decode' hypothesis, it is also possible that those subjects who are better able to integrate non-diagetic information tend to have a more enjoyable presence experience during gaming and thus keep playing this type of game for longer periods.

\subsection{Cognitive factors as predictors of self-rated presence importance}

The two cognitive factors (thematic inertia and the capacity to integrate non-diagetic information) show a significant correlation with each other $(r=0.36$; $n=101$; $\mathrm{p}<$ 0.01). This supports the notion that they share some common cognitive basis. To determine if these cognitive factors are related to presence, we used them as predictors for self-rated presence importance in a multiple regression analysis. This gives a significant model $(\mathrm{F}=12.49$; $\mathrm{df}=2$, 98; $\left.p<0.0001 ; \mathrm{R}^{2}=.202\right)$. In this model, only integration of nondiagetic information is a significant predictor (partial $\mathrm{r}=$ $0.34 ; \mathrm{t}(98)=3.56 ; p<0.0005)$. When we examined the effect of thematic inertia on self-rated presence importance on an item-by-item basis (controlling for the integration of nondiagetic information), we found it to be a significant predictor of two items: "I prefer games which create a sense of being in a place." (partial $\mathrm{r}=0.29$; $\mathrm{t}(78)=2.45 ; p<0.016$; $\left.\mathrm{R}^{2}=0.16\right)$ and "For me, the most important aspect of game playing is the ability to explore other worlds." (partial $\left.\mathrm{r}=0.25 ; \mathrm{t}(78)=2.32 ; p<0.022 ; \mathrm{R}^{2}=0.16\right)$.

\section{Discussion}

\subsection{Learning and experience in presence}

Although this is only an exploratory study and cannot show causation, the data show some interesting trends with regard to experience in VEs and cognition in presence. Firstly, it seems that the most reliable time or learning related predictor of how important players consider presence in gaming to be, is the proportion of their gaming time spent playing presence games. It seems that presence displays a slow-decay effect: one presence experience leads to the desire to have another (this is supported in part by the positive relationship between thematic inertia and some of the presence importance items). Then, if no gaming occurs for a period, the benefit decays (this is indicated by the fact that while frequency of presence game playing is positively associated with presence, length of time having played presence games does not). The data does not seem to indicate that users become desensitized to the presence experience over time. This is inferred from the general lack of effect of the length of time playing presence games. 
Indeed, the opposite may be true, as age has a weak positive effect on self-rated presence importance.

\subsection{Presence maximization strategies}

With regards to presence maximization, the data suggest that gamers do successfully engage in strategies to maximize their presence. Interestingly, these efforts generally vary (inversely) with knowledge of how games work. We propose two explanations for this phenomenon: one is that as gamers' knowledge about the technical aspects of the game interferes with their ability to suspend their disbelief during play. The other is that all gamers have naïve theories of how presence 'works', but more experienced gamers (who probably obtain most of their knowledge from gaming websites and gaming magazines) believe the common game marketing line that the software is largely responsible for presence, and thus make no effort to control their own environment. We would need to explicitly tap into these naïve theories to validate this hypothesis. Regardless of what gamers believe about the causality of their presence experiences, it seems that the presence maximization techniques do have some effect, although with very little consistency.

These findings may be partly obscured by economic factors which we did not take into account. One of the two presence maximization strategies we measured was the maintenance of up-to-date computer hardware. It is likely that the gamers in our sample would like to buy the newest hardware, but as almost all were university students, their economic realities would interfere. Evidence for this comes from the comparison of the item which measures real money expenditure (in which no time effect was found), with the item which measured hypothetical expenditure (for which length of time playing presence games was a predictor). This implies that long-time players of presence games recognize the importance of maintaining updated hardware, but may not always be capable of doing so in practice.

\subsection{Cognitive styles in presence}

We found some evidence of cognitive styles associated with self-rated presence importance, although it is not clear if these develop through playing presence games, or if their prior existence leads to an increase in playing presence games. Of the two cognitive factors we examined, the ability to construct coherent presence experiences from both diagetic and non-diagetic information sources seemed to be the most important to presence experiences. As this capacity improves with presence game playing experience, it seems that in general presence game experience (while controlling for age) leads to more presence. This corresponds to some extent with the positive age/presence relationship reported by [3].

\subsection{The role of sound in presence experiences}

An interesting finding arises from the data about the importance of sound which is worth mentioning.
Players' ratings of the importance of sound to the game experience were not linked to presence management strategies (while ratings of the importance of graphics were). However, the importance of sound was strongly linked to frequency of presence game playing. This may imply that the integration of sound into the presence experience is not affected by a player's efforts, but does improve with repeated exposure. This may suggest that the contribution of sound to presence is processed separately from other modalities, as suggested by [8].

\section{References}

[1] D. Nunez and E. H. Blake, Conceptual priming as a determinant of presence in virtual environments., 2nd International Conference on Computer Graphics, Virtual Reality, Visualisation and Interaction in Africa (AFRIGRAPH 2003), Cape Town, South Africa, 2003, pp. 101-108.

[2] S. Brown, I. Ladeira and C. Winterbottom, The Effects of Mediation in a Storytelling Virtual Environment., International conference on storytelling 2003, 2003, pp. 102-111.

[3] C. Youngblut and B. T. Perrin, Investigating the relationship between presence and task performance in virtual environments., IMAGE 2002 Conference, Scottsdale, AZ., 2002.

[4] M. K. A. Usoh, M. Whitton, R. Bastos, A. Steed, M. Slater and F. P. Brooks, Walking > Walking-in-place > flying, in virtual environments., Computer Graphics Annual Conference (SIGGRAPH99), Los Angeles, CA., 1999, pp. 359-364.

[5] M. Meehan, B. Insko, M. Whitton and F. P. Brooks, Physiological measures of presence in stressful virtual environments., SIGGRAPH 2002, San Antonio, USA, 2002, pp. 645-652.

[6] R. Rosenthal and R. L. Rosnow, Essentials of behaviour research: Methods and data analysis., McGraw Hill, New York, NY, 1991.

[7] W. Wirth, P. Vorderer, T. Hartmann, C. Klimmt, H. Schramm and S. Böcking, Constructing presence: Towards a two-level model of the formation of spatial presence experiences, 6th Annual International Workshop on Presence, Aalborg, Denmark, 2003.

[8] D. Nunez, Working memory and presence: Reconsidering the role of attention in presence., 7 th International workshop on presence (PRESENCE 2004), Valencia, Spain, 2004, pp. 44-47.

[9] B. G. Witmer and M. J. Singer, Measuring presence in virtual environments: A presence questionnaire., Presence: Teleoperators and Virtual Environments., 7 (1998), pp. 78-89.

[10] W. A. IJsselsteijn, H. De Ridder, J. Freeman and S. E. Avons, Presence: Concept, determinants and measurement., Proceedings of the SPIE, 2000, pp. 520529.

[11] D. E. Rumelhart and A. Ortony, The representation of knowledge in memory., in R. C. Anderson, R. J. Spiro and W. E. Montage, eds., Schooling and the Acquisition of Knowledge, Lawrence Erlbaum Associates, 1977. D. Nunez, A constructionist cognitive model of presence., 7th International workshop on presence. (PRESENCE 2004), Valencia, Spain, 2004, pp. 313-316.

[13] D. Bordwell, A case for cognitivism., Iris, 9 (1989), pp. $11-40$. 